\title{
Non-linear simulation of load-bearing capacity for steel-encased concrete piles
}

\author{
G.L.Gorynin \\ Department of Construction Engineering \\ Surgut State University \\ Surgut, Russia \\ ggorynin@list.ru
}

\author{
V.A.Snigireva \\ Department of Construction Engineering \\ Surgut State University \\ Surgut, Russia \\ snow-vera@mail.ru
}

\begin{abstract}
This paper is devoted to simulation of the stressstrain state of a steel-encased concrete piles. Often, the use of steel-encased concrete piles is the most technologically advantageous, especially when large-sized structures are built in difficult ground conditions. However, traditional concrete-filled steel tube structures have a significant disadvantage. The expansion of the concrete is less than the expansion of the steel tube in radial direction. Thus, the steel tube is not in a contact anymore with the concrete. The article proposes the construction of steel-encased concrete piles, inside which concrete is comprehensively compressed by the tube. It is named a concrete end-bearing pile in the steel cage. Now there is no reliable model for steel-encased concrete pipes, which is acceptable for practical use, namely, which fully reflects the features of their stress-strain state and takes into account the nonlinearity of concrete deformation. The article describes the simulation of a nonlinear stress-strain state of concrete confined by a tube. The formulas for the three-dimensional model of a steel-encased concrete endbearing pile considering nonlinearity of a concrete deformation diagram are obtained in this paper. Load-bearing capacity of the concrete end-bearing pile in the steel cage is analyzed. In the article, the effect of the tube wall thickness on the load-bearing capacity of the pile is considered.
\end{abstract}

Keywords- steel-encased concrete pile, concrete-filled steel tube constructions, non-linear concrete deformation diagram

\section{INTRODUCTION}

A steel-encased concrete pile is a steel tube immersed in the ground and filled with a concrete mixture. The technology of erecting such foundations makes it possible to immerse steel-encased concrete piles in constrained difficult conditions, in difficult ground conditions and in the construction of largesized buildings. In work [1], the existing methods for calculating concrete-filled steel tube structures are presented. The observation paper contains the following conclusion "there is no reliable model for concrete-filled steel tube structures in the limiting state that is acceptable for practical use". Therefore, "further research in this area is highly required" since the existing methods do not take into account the thickness of the tube wall and the forces of interaction between concrete and steel.

There are a lot of different opinions about behavior of the steel-encased concrete piles under load. Many scientists suggest that the bearing capacity of concrete-filled steel tube structures is increased, explaining this by strengthening the concrete due to the reactive lateral pressure [2-8]. However, other experimental studies indicate the breaking of contact between the concrete core and the steel tube, as was the case in the operation of the pipe-concrete bridge across the Iset river [9]. In 1991, the book of L. Storozhenko "Calculation of concrete-filled steel tube structures" was published. The book describes an attempt to consider the problem of compression of a concrete-filled steel tube column as a spatial problem in the theory of elasticity [7]. However, the author made a mathematical error in the calculations and thus made the incorrect conclusion that the steel tube is always in a contact with the concrete. Many of the leading researchers refer to the works of L. Storozhenko [2, 8, 9], but due to the presence of the error, this work does not help clarify the question of the spatial work of concrete-filled steel tube structures. In addition, concrete is a non-linearly deformable material, and it is necessary to take this feature into account in the spatial simulation of the stress-strain state of steel-encased concrete piles.

\section{METHODS}

\section{A. Simulation of the stress-strain state of concrete in the nonlinear case}

Simulation of the stress-strain state of concrete in the general case is a complex and unsolved problem because concrete has a non-linearity of deformation. In addition, a complex spatial stress-strain state is characteristic for concrete, which is part of steel-encased concrete piles due to interaction with the steel tube. Let us suppose that the steelencased concrete end-bearing pile is under the action of axial compressive force P. It is assumed that the stress-strain state of the structure has axial symmetry and longitudinal displacements $\mathrm{W}$ depend only on coordinate $\mathrm{z}$, and radial displacements $U$ - on $r$, where " $z, \theta, r$ " is the cylindrical coordinate system (Fig. 1). In this case, normal stresses $\sigma_{r r}, \sigma_{\theta \theta}, \sigma_{z z}$, arise, and tangential stresses do not arise. 


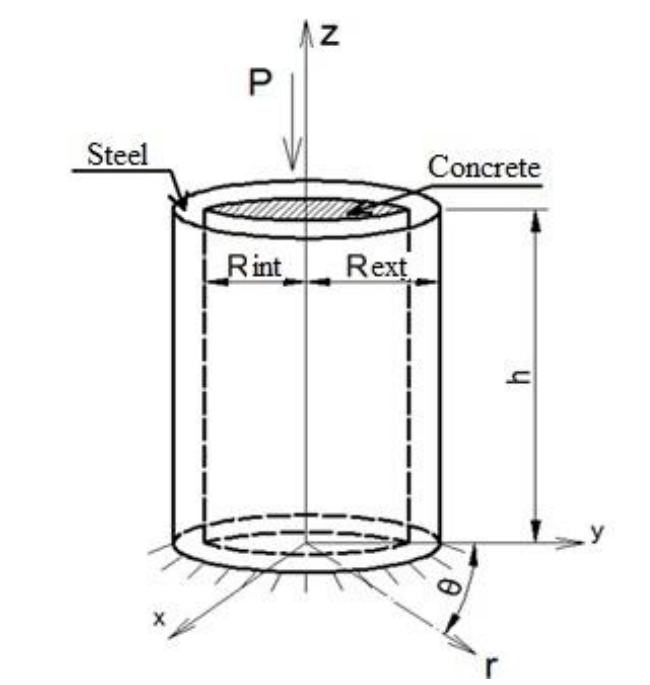

A)

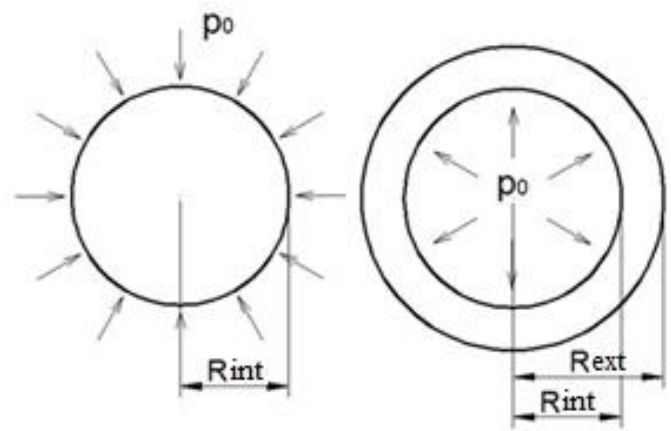

(C)

(S)

B)

C)

Fig.1. The design model; A) a concrete-filled steel tube end-bearing pile; B) the concrete core cross section of the pile; C) the steel tube cross section of the pile

To take into account the non-linearity of concrete deformation as a state diagram, determining the relationship between stresses and deformations, let us use a three-line diagram (Fig. 2) describing a uniaxial stress-strain state, according to the Construction Norms and Regulations 63.13330.2012 "Concrete and reinforced concrete structures". There are no recommendations for taking into account the spatial stress-strain state of concrete in the Construction Norms and Regulations. Let us consider the proposed threeline diagram of uniaxial compression of concrete (Fig. 2): when $\sigma<\sigma^{*}=0,6 R_{b}: \sigma=E \varepsilon \quad$ (section $0-1$ ); when $0,6 R_{b} \leq \sigma<R_{b}: \sigma=\sigma^{*}+\Delta \sigma \quad$ (section 1-2), $\Delta \sigma$ - stress difference, $R_{b}$ - design resistance of concrete under uniaxial compression. Many authors suggest a design model that takes into account the non-linearity of concrete deformation, but the methods vary, because they are based on empirical dependencies [10].
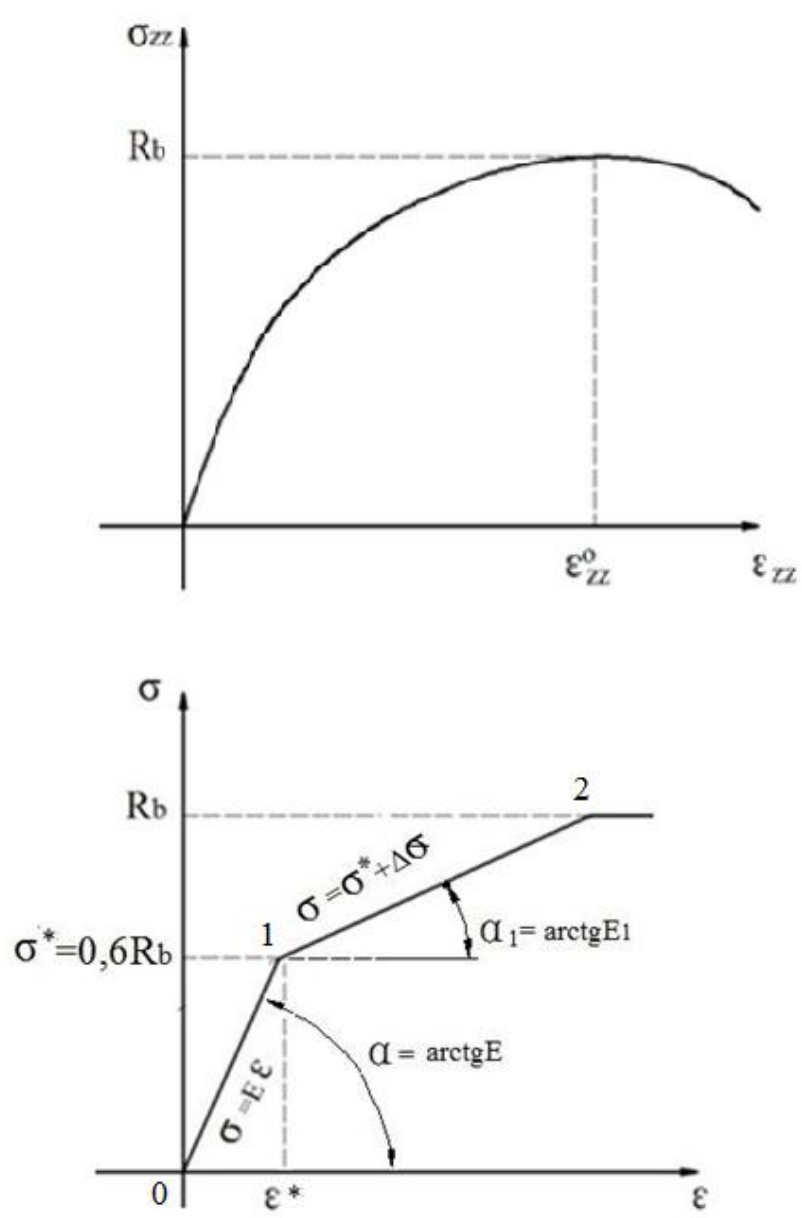

Fig.2. Real and three-line diagrams of concrete deformation in uniaxial compression

(Stresses and deformations are used without taking into account the sign)

Let us make a natural assumption that the stresses in the radial and tangential directions of the concrete core of the steel-encased concrete end-bearing pile are much less than the axial stresses. Therefore, uniaxial stress-strain states, when radial and tangential stresses act separately, always correspond to section $0-1$ of diagram $\left(\sigma<0,6 R_{b}\right)$ (Fig.2). But in the direction of the z-axis, two cases of a uniaxial stress-strain state are possible. Case 1: $\sigma_{z z}<0,6 R_{b}$ (section 0-1); or case 2: $0,6 R_{b} \leq \sigma_{z z}<R_{b}$ (section 1-2). At the initial stage (case $1)$, all components of the stress tensor $\sigma_{r r}, \sigma_{\theta \theta}, \sigma_{z z}$ linearly depend on deformations, i.e. Hooke's law is valid (Fig. 2):

$$
\left\{\begin{array}{l}
\sigma_{r r}=\frac{E}{(1-2 v)(1+v)}\left((1-v) \cdot \varepsilon_{r r}+v \varepsilon_{z z}+v \varepsilon_{\theta \theta}\right) \\
\sigma_{z z}=\frac{E}{(1-2 v)(1+v)}\left((1-v) \cdot \varepsilon_{z z}+v \varepsilon_{r r}+v \varepsilon_{\theta \theta}\right) \\
\sigma_{\theta \theta}=\frac{E}{(1-2 v)(1+v)}\left((1-v) \cdot \varepsilon_{\theta \theta}+v \varepsilon_{r r}+v \varepsilon_{z z}\right)
\end{array}\right.
$$


where $E, v-$ Young's modulus and Poisson's ratio of concrete.

Let us consider case 2. In this state, the stresses and deformations in concrete are determined by dependences:

$$
\begin{gathered}
\sigma_{\mathrm{rr}}=\sigma_{r r}^{*}+\Delta \sigma_{\mathrm{rr}} ; \quad \sigma_{\theta \theta}=\sigma_{\theta \theta}^{*}+\Delta \sigma_{\theta \theta} ; \sigma_{z z}=\sigma_{z z}^{*}+\Delta \sigma_{z z}, \\
\varepsilon_{\mathrm{rr}}=\varepsilon_{r r}^{*}+\Delta \varepsilon_{\mathrm{rr}} ; \quad \varepsilon_{\theta \theta}=\varepsilon_{\theta \theta}^{*}+\Delta \varepsilon_{\theta \theta} ; \quad \varepsilon_{z z}=\varepsilon_{z z}^{*}+\Delta \varepsilon_{z z},
\end{gathered}
$$

where $\sigma_{r r}^{*}, \sigma_{\theta \theta}^{*}, \sigma_{z z}^{*}, \varepsilon_{r r}^{*}, \varepsilon_{\theta \theta}^{*}, \varepsilon_{z z}^{*}$ - values of stresses and deformations, when $\quad \sigma_{z z}=0,6 R_{b}$

$\Delta \sigma_{r r}, \Delta \sigma_{\theta \theta}, \Delta \sigma_{z z}, \Delta \varepsilon_{r r}, \Delta \varepsilon_{\theta \theta}, \Delta \varepsilon_{z z}-$ increments of stresses and deformations respectively.

Let us set that the deformation increments caused by the simultaneous action of radial, tangential and axial stress. Increments are the sum of the deformation increments caused by the action of these stress increments separately. Thus the generalized relations of the deformation increments have the form:

$$
\left\{\begin{array}{l}
\Delta \varepsilon_{r r}=\frac{\Delta \sigma_{r r}}{E}-v \frac{\Delta \sigma_{\theta \theta}}{E}-v_{1} \frac{\Delta \sigma_{z z}}{E_{1}} ; \\
\Delta \varepsilon_{\theta \theta}=-v \frac{\Delta \sigma_{r r}}{E}+\frac{\Delta \sigma_{\theta \theta}}{E}-v_{1} \frac{\Delta \sigma_{z z}}{E_{1}} \\
\Delta \varepsilon_{z z}=-v_{2} \frac{\Delta \sigma_{r r}}{E}-v_{2} \frac{\Delta \sigma_{\theta \theta}}{E}+\frac{\Delta \sigma_{z z}}{E_{1}}
\end{array}\right.
$$

where $E, v$ and $E_{1}, v_{l}-$ Young's modulus and Poisson's ratio of concrete, when the stress values correspond to sections $0-1$ or $0-2$ of the diagram, respectively.

Relations (3) are analogous to Hooke's law for an orthotropic elastic body, the symmetry of the matrices of elastic constants implies the fulfillment of the relation:

$$
\frac{v_{1}}{E_{1}}=\frac{v_{2}}{E}
$$

Let us express the stress increments through the deformation increments from formulas (3), (4). Then equalities (2) and (5) are the spatial law of the stress-strain state of the concrete core of the steel-encased concrete pile when $\sigma_{z z} \geq 0,6 R_{b}$ (case 2).

$$
\left\{\begin{array}{l}
\Delta \sigma_{\mathrm{rr}}=\Delta \varepsilon_{\mathrm{rr}}\left(\frac{E}{1-v^{2}}+\frac{E^{2} v_{1}^{2}}{(1-v)\left(E_{1}(1-v)-2 v_{1}^{2} E\right)}\right)+ \\
+\Delta \varepsilon_{\theta \theta}\left(\frac{E v}{1-v^{2}}+\frac{E^{2} v_{1}^{2}}{(1-v)\left(E_{1}(1-v)-2 v_{1}^{2} E\right)}\right)+ \\
+\Delta \varepsilon_{\mathrm{zz}} \frac{E E_{1} v_{1}}{E_{1}(1-v)-2 v_{1}^{2} E} ; \\
\Delta \sigma_{\theta \theta}=\Delta \varepsilon_{\theta \theta}\left(\frac{E}{1-v^{2}}+\frac{E^{2} v_{1}^{2}}{(1-v)\left(E_{1}(1-v)-2 v_{1}^{2} E\right)}\right)+ \\
+\Delta \varepsilon_{r r}\left(\frac{E v}{1-v^{2}}+\frac{E^{2} v_{1}^{2}}{(1-v)\left(E_{1}(1-v)-2 v_{1}^{2} E\right)}\right)+ \\
+\Delta \varepsilon_{\mathrm{zz}} \frac{E E_{1} v_{1}}{E_{1}(1-v)-2 v_{1}^{2} E} ; \\
\Delta \sigma_{z z}=\frac{E_{1}^{2}(1-v)}{E_{1}(1-v)-2 v_{1}^{2} E}\left(\Delta \varepsilon_{z z}+\frac{E v_{1}}{E_{1}(1-v)}\left(\Delta \varepsilon_{r r}+\Delta \varepsilon_{\theta \theta}\right)\right.
\end{array}\right)
$$

\section{B. Traditional steel-encased concrete end-bearing pile}

Let us represent the solution of the problem of compressing the traditional steel-encased concrete piles. Because of the axisymmetry of the problem, one of the equilibrium equations becomes identity, while the remaining two simplify and have the form:

$$
\frac{\partial \sigma_{r r}}{\partial r}+\frac{\sigma_{r r}-\sigma_{\theta \theta}}{r}=0, \frac{\partial \sigma_{z z}}{\partial z}=0
$$

In the future to indicate the physical characteristics related to the steel tube the superscript "S" and to the concrete - the superscript "C" are used,

Load $\mathrm{P}$ is acting on the entire cross-section. There are no longitudinal displacements of the points on the lower end of the end-bearing pile, this is due to an anchorage of the end (Fig. 1), so the boundary conditions at the ends of the endbearing pile have the form:

$$
W=0(\text { when } z=0) ; \int_{F} \sigma_{z z} d F=-P(\text { when } z=h) \text {. }
$$

Let us assume that there is no lateral pressure on the outer cylindrical surface of the steel tube. Then the boundary condition on the lateral surface is valid (Fig. 1):

$$
\sigma_{r r}^{S}=0 \quad(\text { when } \mathrm{r}=\mathrm{Rext})
$$

To ensure the joint operation of the steel tube-shell and the concrete cylinder, it is necessary to fulfill the conditions of layer interfacing (Fig.1):

$$
\sigma_{r r}^{C}=\sigma_{r r}^{S}, U^{C}=U^{S}, W^{C}=W^{S} \text { (when r=Rint) }
$$

Let us introduce the following notation: 
$p_{0}$ - radial pressure at the contact of the layers, then $\sigma_{r r}^{C}=\sigma_{r r}^{S}=-p_{0}$ (when $\mathrm{r}=\mathrm{Rint}$ ), $p^{C}, p^{S}-$ longitudinal (along the $\mathrm{z}$-axis) compressive pressures are applied to the concrete core and steel tube, respectively.

The stress-strain state of the tube material corresponds to the generalized Hooke's law (1).

Let us consider the operation of the pile when the stressstrain state of concrete corresponds to case 1. Problem (1), (6) - (9) is the problem of the spatial theory of elasticity in the formulation of Saint-Venant; the solution of problems of this type is considered in the articles $[11 ; 12]$. The solutions of the problems (1), (6) - (8) for the steel tube and the concrete core, separately taking into account the first equation for the stresses (9) and without taking into account the second and the third equalities has the form:

$$
\left\{\begin{array} { l } 
{ \sigma _ { r r } ^ { S } = \frac { p _ { 0 } \cdot R _ { \mathrm { int } } ^ { 2 } \cdot ( r ^ { 2 } - R _ { e x t } ^ { 2 } ) } { ( R _ { e x t } ^ { 2 } - R _ { \mathrm { int } } ^ { 2 } ) \cdot r ^ { 2 } } ; } \\
{ \sigma _ { z z } ^ { S } = - p ^ { S } ; } \\
{ \sigma _ { \theta \theta } ^ { S } = \frac { p _ { 0 } \cdot R _ { \mathrm { int } } ^ { 2 } \cdot ( r ^ { 2 } + R _ { e x t } ^ { 2 } ) } { ( R _ { e x t } ^ { 2 } - R _ { \mathrm { int } } ^ { 2 } ) \cdot r ^ { 2 } } }
\end{array} \quad \left\{\begin{array}{l}
\sigma_{r r}^{C}=-p_{0} \\
\sigma_{z z}^{C}=-p^{C} \\
\sigma_{\theta \theta}^{C}=-p_{0}
\end{array}\right.\right.
$$

Taking into account the second and the third equalities of the conditions of layer interfacing (9) and the equalities (7), the solution of problem (1), (6) - (9) is obtained:

$$
\begin{aligned}
& p^{C}=p_{0} \cdot\left(\frac{\left(1-2 v^{C}\right) \cdot\left(1+v^{C}\right)}{\left(v^{C}-v^{S}\right)}+2 v^{C}+\right. \\
& \left.+\frac{E^{C}}{E^{S}} \cdot \frac{R_{\mathrm{int}}^{2}\left(1-2 v^{S}\right) \cdot\left(1+v^{S}\right)+R_{e x t}^{2}\left(1+v^{S}\right)}{\left(v^{C}-v^{S}\right) \cdot\left(R_{e x t}^{2}-R_{\mathrm{int}}^{2}\right)}\right), \\
& p^{S}=p_{0} \cdot\left(\frac{E^{S}}{E^{C}} \frac{\left(1-2 v^{C}\right) \cdot\left(1+v^{C}\right)}{\left(v^{C}-v^{S}\right)}+\right. \\
& \left.+\frac{R_{\mathrm{int}}^{2}\left(1-v^{S}\right)+R_{e x t}^{2}\left(1+v^{S}\right)-2 R_{\mathrm{int}}^{2} v^{S} v^{C}}{\left(v^{C}-v^{S}\right) \cdot\left(R_{e x t}^{2}-R_{\mathrm{int}}^{2}\right)}\right), \\
& p_{0}=P \cdot \frac{E^{C} E^{S}\left(v^{C}-v^{S}\right)\left(R_{e x t}^{2}-R_{\mathrm{int}}^{2}\right)}{\alpha}, \\
& \alpha=\pi R_{\mathrm{int}}^{2} E^{C}\left(E^{S}\left(1-v^{C}-2 v^{C} v^{S}\right)\left(R_{e x t}^{2}-R_{\mathrm{int}}^{2}\right)+\right. \\
& +\pi\left(R_{e x t}^{2}-R_{\mathrm{int}}^{2}\right) E^{S}\left(E^{S}\left(1-2 v^{C}\right)\left(1+v^{C}\right)\left(R_{e x t}^{2}-R_{\mathrm{int}}^{2}\right)+\right. \\
& \left.+E^{C}\left(R_{\mathrm{int}}^{2}\left(1-v^{S}-2 v^{S} v^{C}\right)+R_{\text {ext }}^{2}\left(1+v^{S}\right)\right)\right)
\end{aligned}
$$

Let us analyze the obtained dependences and draw the main conclusions:

1. According to formula (11), compression pressure sign $\mathrm{p}_{0}$ is completely determined by the difference in Poisson's coefficients of concrete and steel $\left(v^{C}-v^{S}\right)$.

2. Poisson's ratio of concrete and steel are $v^{C}=0.2$ and $v^{s}=0.3$ respectively. Therefore, compression pressure $p_{0}<0$ and the radial stresses in the concrete core are tensile (10), which leads to a break of contact between the concrete core and the steel tube, and therefore, the joint work of concrete and steel is not realized. This is an incurable disadvantage of traditional steel-encased concrete piles. This fact is also confirmed when calculating the traditional constructions taking into account the nonlinear deformation of concrete.

\section{Concrete end-bearing pile in steel cage}

Since traditional concrete-filled steel tube structures have a significant disadvantage, as mentioned above, the different steel-encased concrete pile is proposed. It is a concrete endbearing pile in a steel cage. When using this structure, the external load is applied only to the concrete core, and the tube is used as a cage, while the joint work of the concrete core and the steel tube in the longitudinal direction is excluded.

Let us consider the operation of the structure when the stressed state of concrete corresponds to case 1. Equations of equilibrium (6) and Hooke's law (1) for concrete and steel and the boundary condition on the lateral surface (8) remain in effect in the formulation of this problem, but the boundary conditions at the ends of (7) vary and have the form:

$$
W=0(\text { when } z=0) ; \int_{F^{C}} \sigma_{z z} d F=-P(\text { when } z=h) \text {. }
$$

In this design, there is no joint work of the concrete core and the steel tube in the longitudinal direction, and the interaction in the transverse direction is performed according to the following conditions of layer interfacing:

$$
\sigma_{r r}^{C}=\sigma_{r r}^{S}, U^{C}=U^{S} \text { (when r=Rint) }
$$

The boundary problem (1), (6), (8), (12), (13) is the problem of the spatial theory of elasticity in the formulation of Saint-Venant. The solution of problems (1), (6), (8), (12) for a steel tube and a concrete core separately, taking into account the fact that the longitudinal pressure acts only on concrete, and there is no joint work of the layers (13), is obtained:

$$
\left\{\begin{array} { l } 
{ \sigma _ { r r } ^ { S } = \frac { p _ { 0 } \cdot R _ { \mathrm { int } } ^ { 2 } \cdot ( r ^ { 2 } - R _ { e x t } ^ { 2 } ) } { ( R _ { e x t } ^ { 2 } - R _ { \mathrm { int } } ^ { 2 } ) \cdot r ^ { 2 } } ; } \\
{ \sigma _ { z z } ^ { S } = - p ^ { S } ; } \\
{ \sigma _ { \theta \theta } ^ { S } = \frac { p _ { 0 } \cdot R _ { \mathrm { int } } ^ { 2 } \cdot ( r ^ { 2 } + R _ { e x t } ^ { 2 } ) } { ( R _ { e x t } ^ { 2 } - R _ { \mathrm { int } } ^ { 2 } ) \cdot r ^ { 2 } } . }
\end{array} \left\{\begin{array}{l}
\sigma_{r r}^{C}=-p_{0} ; \\
\sigma_{z z}^{C}=-p^{C}=-\frac{P}{F^{C}} ; \\
\sigma_{\theta \theta}^{C}=-p_{0} .
\end{array}\right.\right.
$$

Equations (14) are obtained only with the use of equilibrium equations and do not depend on the linearity or nonlinearity of the concrete deformation law. The magnitude of the interaction pressure of the layers $p_{0}$ depends on the nature of the material deformation.

Taking into account the conditions of layer interfacing (13) and the equalities (12), the solution of the problem $((1),(6)$, (8), (12), (13) is obtained, in which the stress-strain state of concrete corresponds to the law (1) (case 1): 


$$
\begin{aligned}
& p_{0}=\frac{P}{\pi R_{\mathrm{int}}^{2}} . \\
& \cdot \frac{E^{S} v^{C}\left(R_{e x t}^{2}-R_{\mathrm{int}}^{2}\right)}{E^{C}\left(R_{\mathrm{int}}^{2}\left(1-v^{S}\right)+R_{e x t}^{2}\left(1+v^{S}\right)\right)+E^{S}\left(R_{e x t}^{2}-R_{\mathrm{int}}^{2}\right)\left(1-v^{C}\right)} .
\end{aligned}
$$

It follows from formula (15) that the compression pressure $p_{0}$ is always a positive value, hence the radial stresses in the concrete core are compressive, the concrete is in a state of triaxial compression (according to formula (14)). This fact has a positive effect on increasing the strength of the concrete core, as shown by the experiments of the researchers $[13 ; 14$; $15 ; 16]$.

Let us consider the operation of the pile when the stress state of concrete corresponds to case 2, that is, taking into account the nonlinearity of the concrete deformation diagram.

In the future, to denote the values related to the solution of the problem, taking into account the nonlinearity of the concrete deformation diagram, the superscript " $n$ ", and when considering the deformation of concrete according to Hooke's linear law - the superscript "1" will be used.

Taking into account the conditions of layer interfacing (13) and the solutions obtained for the independently operating steel cage and the concrete cylinder (14), the solution of the non-linear problem (1), (2), (5), (6), (8), (12), (13) is obtained, in which the stress-strain state of concrete obeys law (2), (5) (case 2):

$$
\begin{aligned}
& p^{n}{ }_{0}=\left(\frac{P}{\pi R_{\mathrm{int}}^{2}} \cdot \frac{v_{1}^{C}}{E_{1}^{C}}+\frac{E^{C} v_{1}^{C}-E_{1}^{C} v^{C}}{E_{1}^{C}\left(1-2 v^{C}\right)\left(1+v^{C}\right)} \cdot\left(v^{C} \varepsilon_{r r}^{*}+\right.\right. \\
& \left.\left.+v^{C} \varepsilon_{\theta \theta}^{*}+\left(1-v^{C}\right) \varepsilon_{z z}^{*}\right)\right) \cdot \\
& \cdot \frac{E^{C} E^{S}\left(R_{e x t}^{2}-R_{\mathrm{int}}^{2}\right)}{E^{S}\left(1-v^{C}\right)\left(R_{e x t}^{2}-R_{\mathrm{int}}^{2}\right)+E^{C}\left(\left(1-v^{S}\right) R_{e x t}^{2} R_{\mathrm{int}}^{2}+\left(1+v^{S}\right) R_{e x t}^{2}\right)}
\end{aligned}
$$

$$
R_{b, 3}=R_{b}+K \cdot p_{0}
$$

where $R_{b, 3}$ - design resistance of concrete under three-axial compression, $K$ - concrete strengthening coefficient $K \approx 4$ [2].

Thus, the formula for determining the strength of concrete under triaxial compression has the form:

$$
R_{b, 3}=R_{b}+4 \cdot p_{0}
$$

\section{B. An example}

Let us consider an example of calculation of a concretefilled steel tube end-bearing pile. Two different approaches are compared: the nonlinear model of the concrete deformation diagram (case 2) and the linear model (case 1). Different thickness of the tube wall and $R_{\text {int }}=0.315 \mathrm{~m}$ are taked. The deformation-strength characteristics of materials are assumed according to the Construction Norms and Regulations 63.13330.2012 "Concrete and reinforced concrete structures" and Construction Norms and Regulations 16.13330.2011 "Steel Structures": $E^{C}=30000 \mathrm{MPa}, E_{l}{ }^{C}=8571.4 \mathrm{MPa}, v^{C}=$ $0.2, v_{1}^{C}=0.2, \mathrm{Rb}=14.5 \mathrm{MPa}$ (concrete B 25) and $E^{S}=206000$ $\mathrm{MPa}, \quad v^{s}=0.3$.

The results are presented in Table 1 , where $\Delta$ is the increment of pressure. For example, when the wall thickness is $4 \mathrm{~mm}$, the maximum value $P_{3}^{n}=5.27 \mathrm{MN}, P_{3}^{i}=4.83 \mathrm{MN}$, and the values of the design resistance of concrete under threeaxial $R_{b, 3}^{n}=16.92 \mathrm{MPa}, R_{b, 3}^{l}=15.50 \mathrm{MPa}$ (Fig.3).

TABLE 1. Results OF CALCULATIONS WHEN $v^{C}=0,2, v_{1}^{C}=0,2$

\begin{tabular}{|c|c|c|c|c|c|c|}
\hline $\begin{array}{c}\text { Tube } \\
\text { wall } \\
\text { thickness, } \\
\text { mm }\end{array}$ & $\frac{\Delta p_{0}^{\mathrm{l}}}{\Delta p^{\mathrm{C}}}$ & $\frac{\Delta p_{0}^{\mathrm{n}}}{\Delta p^{\mathrm{C}}}$ & $\frac{\max p_{0}^{\mathrm{n}}}{\max _{0}^{\mathrm{l}}}$ & $\frac{\boldsymbol{R}_{b, 3}^{\mathrm{l}}}{\boldsymbol{R}_{b}}$ & $\frac{\boldsymbol{R}_{b, 3}^{\mathrm{n}}}{\boldsymbol{R}_{b}}$ & $\frac{\boldsymbol{R}_{b, 3}^{\mathrm{n}}}{\boldsymbol{R}_{b, 3}^{\mathrm{l}}}$ \\
\hline 4 & 0.02 & 0.06 & 2.42 & 1.07 & 1.17 & 1.09 \\
\hline 4.5 & 0.02 & 0.06 & 2.48 & 1.08 & 1.19 & 1.11 \\
\hline 5 & 0.02 & 0.07 & 2.55 & 1.09 & 1.22 & 1.12 \\
\hline 10 & 0.04 & 0.13 & 3.48 & 1.17 & 1.59 & 1.36 \\
\hline
\end{tabular}

\section{RESULTS AND DISCUSSION}

\section{A. Increasing the load-bearing capacity of concrete under comprehensive compression}

Let us analyze the increase in the load-bearing capacity of a concrete end-bearing pile in a steel cage due to strengthening of the concrete core. The most common form of presenting the strength of concrete under a three-axis contraction is the formula proposed by F. Richard, A. Brown and A. Brandraeg [14]: 


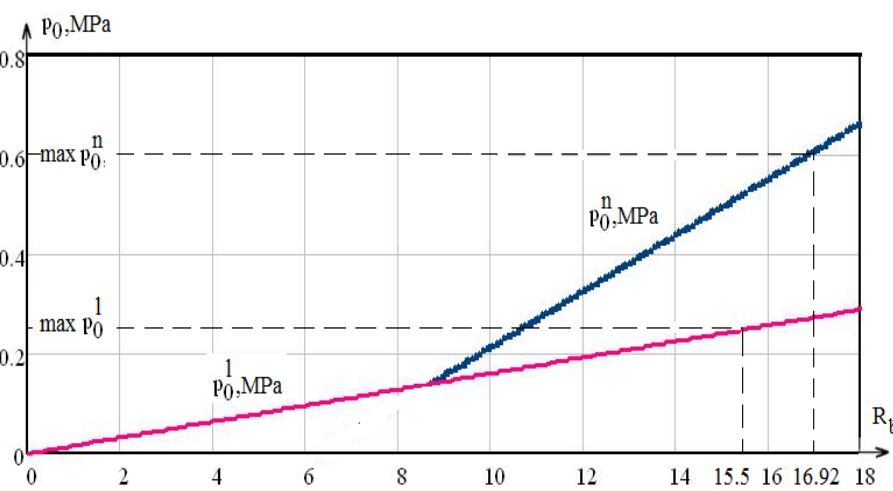

Fig.3 - Dependence of the radial compression pressure on the axia compressive pressure on concrete when $v^{\mathrm{C}}=v_{1}^{\mathrm{C}}=0,2$, and the wall thickness of the tube is $4 \mathrm{~mm}$.

According to the results (Table 2) and the presented graph (Fig. 3), the calculated compression pressure of concrete is underestimated. Thus the design load-bearing capacity of the pile is also underestimated as the result of calculation by the linear model.

It is known that the Poisson's ratio of concrete is the variable that increases with increasing of load on concrete [5; 17]. Let us perform calculations with the initial data presented above, but the Poisson's ratio of concrete is different $v_{1}^{C}=0.25$. The results are presented in Table 2 . When the wall thickness is $4 \mathrm{~mm}$, the maximum value is $P_{3}^{n}=5.48 \mathrm{MN}$ and the values of the design resistance of concrete under threeaxial are $R_{b, 3}^{n}=17.57 \mathrm{MPa}$.

TABle 2. Results Of CALCULATIONS WhEN $v^{C}=0,2, v_{1}^{C}=0,25$

\begin{tabular}{|c|c|c|c|c|c|c|}
\hline $\begin{array}{c}\text { Tube } \\
\text { wall } \\
\text { thickness, } \\
\text { mm }\end{array}$ & $\frac{\Delta p_{0}^{\mathrm{l}}}{\Delta p^{\mathrm{C}}}$ & $\frac{\Delta p_{0}^{\mathrm{n}}}{\Delta p^{\mathrm{C}}}$ & $\frac{\max _{0}^{\mathrm{n}}}{\max _{0}^{\mathrm{l}}}$ & $\frac{\boldsymbol{R}_{b, 3}^{\mathrm{l}}}{\boldsymbol{R}_{b}}$ & $\frac{\boldsymbol{R}_{b, 3}^{\mathrm{n}}}{\boldsymbol{R}_{b}}$ & $\frac{\boldsymbol{R}_{b, 3}^{n}}{\boldsymbol{R}_{b, 3}^{\mathrm{l}}}$ \\
\hline 4 & 0.02 & 0.07 & 3.07 & 1.07 & 1.21 & 1.13 \\
\hline 4.5 & 0.02 & 0.08 & 3.19 & 1.08 & 1.25 & 1.16 \\
\hline 5 & 0.02 & 0.09 & 3.31 & 1.09 & 1.29 & 1.18 \\
\hline 10 & 0.04 & 0.16 & 5.51 & 1.17 & 1.94 & 1.66 \\
\hline
\end{tabular}

Comparison of the results presented in Tables 1 and 2 shows that in the case when the increase in the Poisson's ratio of concrete is taken into account, the value of the calculated bearing capacity of the concrete core is higher than this value when the calculation is made with an unchanged coefficient.

\section{CONCLUSIONS}

1. The simulation of a nonlinear stress-strain state of concrete confined by a tube is presented.

2. The different steel-encased concrete pile is proposed. It is a concrete end-bearing pile in a steel cage. When using this structure, the concrete is in a state of triaxial compression.
3. The formulas for the three-dimensional stress-strain state of a concrete end-bearing pile in a steel cage considering nonlinearity of concrete deformation diagram are derived and presented in the article.

4. The increase in the load-bearing capacity of a concrete end-bearing pile in a steel cage due to strengthening of the concrete core is analyzed.

5. The design load-bearing capacity of the concrete endbearing pile in a steel cage increases when the features of the non-linear behavior of concrete are taken into account.

6. The design load-bearing capacity of the a concrete end-bearing pile in a steel cage depends on the tube wall thickness and increases with increasing Poisson's ratio of concrete.

\section{References}

[1] I.I. Ovchinnikov, I.G. Ovchinnikov, G.V. Chesnokov, E.S. Mihaldykin "About the problem of calculating concrete-filled steel tube structures with a membrane of different materials. Part 2. Calculation of concretefilled steel tube structures with a metal membrane", Naukovedenie, vol. 7, No 4, pp. 2-29, 2015

[2] A.I. Kikin, R.S. Sanzharovskiy, V.A. Trul', Concrete-filled steel tube structures, Moscow: Stroyizdat, 1974, p. 144.

[3] J.G. Teng, Y.L Huang, L. Lam, "Theoretical model for fiber-reinforced polymer-confined concrete", Journal of Composites for Construction, vol. 11(2), pp. 201-210, 2007

[4] J.G. Teng, Q.G. Xiao, T. Yu, "Three-dimensional finite element analysis of reinforced concrete columns with FRP and/or steel confinement", Engineering Structures, vol. 97, pp. 15-28, 2015.

[5] J. Zhang, S. Jiang, B. Chen, C. Li, H. Qin, "Numerical study of damage modes and damage assessment of CFST columns under blast loading", Shock and Vibration, vol. 2016, pp. 1-12, 2016

[6] A.Z. Fam, S.H. Rizkalla, "Confinement model for axially loaded concrete confined by circular fiber-reinforced polymer tubes", Structural Journal, vol. 98, pp. 451-461, 2001

[7] L.I. Storozhenko, P.I. Plahotniy, A.Ya. Cherniy, Calculation of concretefilled steel tube structures, Kiev: Budivel'nik, 1991, p. 120.

[8] I.V. Rezvan, Concrete-filled steel tube columns made of high-strength self-compacting tensile concrete, The PhD dissertation of Tech.Sci., Rostov-on-Done, 2012, p. 203.

[9] A.L. Kryshan, Strength of pre-compressed core concrete-filled steel tube columns, The DSc dissertation of Tech.Sci., Magnitogorsk, 2011, p. 380.

[10] V. Patel, Q.Q. Liang, M.N.S. Hadi, "Numerical analysis of high-strength concrete-filled steel tubular slender beam-columns under cyclic loading", Journal of Constructional Steel Research, vol. 92, pp. 183-194, 2014.

[11] G.L. Gorynin, Yu.V. Nemirovskii, "Deformation of laminated anisotropic bars in the three-dimensional statement 1.Transverselongitudinal bending and edge compatibility condition", Mechanics of Composite Materials, vol. 45, No 3, pp. 257-280, 2009

[12] G.L. Gorynin, Yu.V. Nemirovskii, "Deformation of laminated anisotropic bars in the three-dimensional statement 2. Effect of edge boundary layers on the stress-strain properties of the composite," Mechanics of Composite Materials, vol. 46, No 1, pp. 130-143, 2010

[13] O.Ya. Berg, G.G. Solomencev, "Investigation of stress and strain state of concrete under triaxial compression", Proceedings of the All-Union Research Institute of transport, construction, vol. 70, pp. 106-123, 1969.

[14] F. Richart, A. Brown, A. Brandraeg, A study of failure of concrete under combined compressive stresses, University Illinois, Eng. Exper. Station. Bull., No 185, 1928, p. 105.

[15] V.K. Papanikolaou, A.J. Kappos, "Confinement-sensitive plasticity constitutive model for concrete in triaxial compression", International Journal of Solids and Structures, vol. 44, No. 21, pp. 7021-7048, 2007. 
[16] M. Attard, S. Setunge, "Stress-strain relationship of confined and unconfined concrete", ACI Materials Journal, vol. 93, No. 5, pp. 432442, 1996.

[17] V.F. Marenin, Investigation of the strength of concrete-filled steel tube structures under axial compression, The PhD dissertation of Tech.Sci., Moscow, 1959, p. 158. 